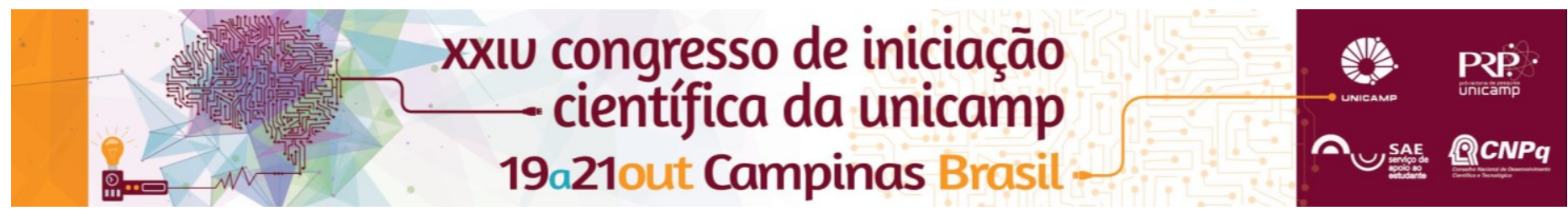

\title{
Educational trajectories and professional expectations among Biology undergraduated students from UNICAMP
}

\author{
Cássio P. Freitas*, Maurício Ernica
}

\begin{abstract}
Undergraduated biologists at UNICAMP develop many trajectories depending on their choice for licenciate or bachelor degree. In this study, differences emerge when we investigate educational and historical trajectories of students and their families, suggesting that social position influences this choice. The similarity of educational programs allows students to transit between the two courses and become postgraduate students, diminishing the social segmentation noted at the graduation's start.
\end{abstract}

\section{Key words:}

education inequality, expectancy, occupation

\section{Introduction}

Biology examines life to understand the functioning of the environment integrating political and economic knowledge to social ecosystem analysis. The biologist, professional dealing with this study, can opt for the bachelor program, aimed at training researchers and technologists, or the licenciate program, focused on training future researchers and teachers.

Given the social origin and school life of Biological Sciences students that graduated at UNICAMP in 2015, we investigated their relationship with higher education and their professional expectations.

\section{Results and Discussion}

Based on socioeconomic questionnaires applied upon entrance in the course by the Permanent Comission of UNICAMP Vestibular (Comvest), we selected variables that could imply the social status and school performance of students. When analyzed, certain patterns were noted and used to select 24 students (15 baccalaureate and 9 licentiated) to be interviewed among the 83 potential trainees.

Licenciate students : are older and most reside in Campinas. Have worked or attended other graduation after public high school. Parents are less educated and family income is low.

Bachelor students : are younger students from middle-income and more educated families. Never worked and did average private education.

Both courses have a third of male students and two thirds of women, and is more common to find black students studying at night to get the licenciate degree. After the interviews, they were divided in 8 groups according to their social origin, educational background and professional perspective.

Students in groups 1,2 and 3 are white, mostly single women who started bachelor's course at ages 17 or 18 and have never worked because their families have high income, more than 10 minimum wages (one minimum wage is around $\mathrm{R} \$ 880,00$ ) and can sustain them comfortably. Their biggest challenge is maintaining high grades that allows them to get scholarships or to apply for exchange programs. Their parents, who have higher education, understand that university is a gateway to prestigious careers along science. Thanks to this support, they expect to work as researchers (group 1) or in private companies (group 2). Those who are oriented towards teaching (group 3) report to have been frustrated by the academy, but believe that the postgraduate titles gives better conditions to compete for a job in the future.

Students from groups 4 and 5 are mostly white coming from private and public schools, oriented for research in biology (group 4) or teaching (group 5). At least one of the parents have higher education, which narrows the relationship between the household and the entrance exam, but the family income, wich varies from 5 to 10 minimum wages, makes some of them start to work or try to obtain scholarships.

Groups 6, 7 and 8 consist on students whose family income reaches until 5 minimum wages per month, and usually worked after high school to help the family income, putting off the course until reaching the age of 20 years old. To enter the university, they turned to popular preparatory courses that help in the task of resuming studies. Being little schooled, their parents and grandparents didn't identify with the university and had the thought that those students should find a job instead of studying, causing many of them to keep a job during part of the course. This routine gets worse among those who have children, companions or live far from the university, which, however, does not prevent them from engaging research in education (group 6) or academic career (group 7), as they believe is the best way to socially ascend. The group 8 intends to study another degree.

\section{Conclusions}

The similarity between the curriculum of the courses allows licenciated to re-enter graduation aas well as attend the baccalaureate course and vice versa, reducing the social gap observed at the beginning of the courses and improving the chances of finding employment.

While socially privileged students complete their courses easily, envision scientific careers without major challenges and devote more time to research routines, those who don't receive parental support or work along their schooling face great barriers to enter in colege and complete their academic lives. 